\title{
Historical cohort study of a New Zealand foundry and heavy engineering plant
}

\author{
H M Firth, J M Elwood, B Cox, G P Herbison
}

\begin{abstract}
Objectives-To investigate the mortality of workers who had been exposed to asbestos, machining fluids and foundry work in a foundry and heavy engineering plant in the railway rolling stock manufacturing industry in New Zealand.

Methods-Historical cohort study design. Results-For the total workforce of 3522 men employed between 1945 and 1991, follow up was $90 \%$ of person-years to 31 December 1991. Significantly increased standardised mortality ratios (SMRs) were found for all causes of death combined (SMR 1.07; 95\% confidence interval (95\% CI) 1.01 to 1.14 ), all malignancies (SMR 1.15; 95\% CI 1.01 to 1.31 ), circulatory (SMR 1.16; 95\% CI 1.07 to 1.27 ) and musculoskeletal diseases (SMR 3.06; 95\% CI 1.39 to 5.84), all digestive cancers (SMR 1.29; $95 \%$ CI 1.04 to 1.59 ), all respiratory cancers (SMR 1.34; 95\% CI 1.08 to 1.65 ), cancer of the oesophagus (SMR 1.97; 95\% CI 1.01 to 3.45), and mesothelioma of the pleura (SMR 6.58; 95\% CI 1.24 to 19.49 ). Three deaths from pleural mesothelioma were recorded, with latency times of 51, 53, and 57 years. There were no doseresponse relations between exposure to asbestos, machining fluids or foundry work, or by duration of employment in the plant, and any cause of death.

Conclusions-This study found small increases in risk for several causes of death among foundry and heavy engineering workers; however, these increases were small and the possible effects of smoking and other lifestyle factors could not be excluded. There was evidence of asbestos related disease in those involved in engineering work in the past.

(Occup Environ Med 1999;56:134-138)
\end{abstract}

Department of

Preventive and Social

Medicine, University

of Otago Medical

School, PO Box 913,

Dunedin, New Zealand

H M Firth

J M Elwood

B Cox

G P Herbison

Correspondence to:

Dr H M Firth, Department

of Preventive and Social

Medicine, University of

Otago Medical School, PO

Box 913, Dunedin, New

Zealand.

Accepted 17 September 1998
Keywords: occupational health; asbestos; machining fluids

Foundry and heavy engineering work is a hazardous occupation which has not been investigated previously in New Zealand. Foundry workers may be exposed to various hazards including air contaminants such as metal dusts, fumes, silica, and polycyclic aromatic hydrocarbons (PAHs), and physical agents such as molten metal and machinery. Engineering workers particularly in machine shops are exposed to machining fluids, and workers in construction and repair shops may be exposed to solvents, welding fumes, and in the past asbestos.
Only one other historical cohort study has ever been carried out in New Zealand and no previous studies have been carried out in New Zealand to examine the mortality of foundry and heavy engineering workers. ${ }^{1}$ Several studies have been carried out in other countries, in various different manufacturing processes to investigate the association between lung cancer and foundry work, and exposure to machining fluids and digestive cancers. ${ }^{2-4}$ The International Agency for Research on Cancer (IARC) has listed foundry work as being carcinogenic to humans with a relative risk for lung cancer in the range $1.5-2.5 .^{25}$ There is currently inadequate evidence as to the carcinogenicity of the highly refined mineral oils. ${ }^{35}$

The association between asbestos and disease is well known although whether chrysotile causes mesothelioma of the pleura is still a matter of some debate. ${ }^{67} \mathrm{Few}$ studies have been carried out elsewhere to investigate the mortality of workers in the railway rolling stock manufacturing industry. ${ }^{89}$

The plant described here manufactures and repairs railway rolling stock, and consists of an iron and steel foundry, and construction, repair, and machine shops. This study, with a historical cohort study design, was undertaken to investigate the mortality experience of railway rolling stock manufacturing workers. The main hypotheses assessed were the associations between foundry work and lung cancer, exposure to machining fluids in machine shops and digestive cancers, and past exposure to asbestos in construction and repair shops and diseases related to asbestos.

\section{Methods}

The cohort was defined as all men who had worked for $\geqslant 3$ months between 1945 and 1991 whose employment record card was held in the personnel department. Full name, date of birth, occupation, changes of occupation, and dates of starting and finishing employment were manually extracted from personnel records.

Exposure status was determined from occupational title, with information from plant records, past and present employees, and a review of the literature. No environmental measurements for asbestos, machining fluids, or foundry air contaminants (such as silica or PAHs) had ever been made at the plant. Each man was classified according to his longest held job, and each job was placed into an exposure category of high, medium, low, or no exposure to asbestos or machining fluids and in the case of foundry work, exposed or not exposed. For example, boilermakers and their assistants 
Table 1 SMRs for major causes of death and respiratory deaths, total workforce

\begin{tabular}{|c|c|c|c|}
\hline Cause of death & $\begin{array}{l}\text { Observed deaths } \\
(n)\end{array}$ & $\begin{array}{l}\text { Expected deaths } \\
(n)\end{array}$ & $S M R(95 \% C I)$ \\
\hline All causes & 996 & 929.76 & $1.07(1.01$ to 1.14$)$ \\
\hline Infectious and parasitic & 6 & 12.13 & $0.49(0.18$ to 1.08$)$ \\
\hline All malignant & 247 & 214.32 & $1.15(1.01$ to 1.31$)$ \\
\hline $\begin{array}{l}\text { Endocrine, nutritional, and } \\
\text { metabolic }\end{array}$ & 7 & 17.91 & $0.39(0.15$ to 0.81$)$ \\
\hline Mental disorders & 5 & 5.10 & $0.98(0.31$ to 2.31$)$ \\
\hline Nervous system and sense organs & 18 & 24.98 & $0.72(0.43$ to 1.14$)$ \\
\hline Circulatory & 518 & 444.87 & $1.16(1.07$ to 1.27$)$ \\
\hline Respiratory & 93 & 83.59 & $1.11(0.90$ to 1.36$)$ \\
\hline All pneumonias & 22 & 22.44 & 0.98 (0.61 to 1.49$)$ \\
\hline $\begin{array}{l}\text { Chronic bronchitis or } \\
\text { emphysema }\end{array}$ & 28 & 22.36 & $1.25(0.83$ to 1.81$)$ \\
\hline Asthma & 4 & 6.75 & $0.59(0.15$ to 1.53$)$ \\
\hline Pneumoconioses & 1 & 0.18 & $5.43(0.00$ to 31.14$)$ \\
\hline Digestive & 16 & 25.82 & $0.62(0.35$ to 1.01$)$ \\
\hline Genitourinary & 11 & 12.26 & $0.90(0.45$ to 1.61$)$ \\
\hline $\begin{array}{l}\text { Musculoskeletal and connective } \\
\text { tissue }\end{array}$ & 9 & 2.94 & $3.06(1.39$ to 5.84$)$ \\
\hline Injury and poisoning & 60 & 76.45 & $0.78(0.60$ to 1.01$)$ \\
\hline Ill defined & 2 & 1.17 & $1.70(0.16$ to 6.27$)$ \\
\hline
\end{tabular}

(holder-uppers) had the highest exposure to asbestos, with fitters having a medium exposure. Turners and machine tool operators had the highest exposure to machining fluids. Metal processors (foundry workers) were employed in an area separate from the engineering workers and had little or no exposure to asbestos. Administrative workers had no exposure to any contaminant. Labourers could not be classified into an exposure category as they could have worked in any area of the plant, and were classified as having a mixed exposure.

In the main repair area of the plant, steam engine boilers were stripped of asbestos, repaired, and re-insulated. This was an extremely dusty job, particularly for boilermakers and holder uppers. No respiratory protection was worn. Steam engines were manufactured and repaired from before the 1930s until 1965, and asbestos was used in diesel engines until 1981. The type of asbestos used in insulating steam engines was chrysotile, although there is one anecdotal report of a small amount of crocidolite being tested for a short time in a different process. In the machine shops, soluble oils were used which by the 1960 s were mainly

Table 2 SMRs for malignant causes of death, total workforce

\begin{tabular}{lrrl}
\hline Cause of death & $\begin{array}{l}\text { Observed deaths } \\
(n)\end{array}$ & $\begin{array}{l}\text { Expected deaths } \\
(n)\end{array}$ & SMR (95\% CI) \\
\hline All cancers & 247 & 214.32 & $1.15(1.01$ to 1.31$)$ \\
Buccal cavity and pharynx & 2 & 4.79 & $0.42(0.04$ to 1.53$)$ \\
All digestive cancers & 90 & 69.69 & $1.29(1.04$ to 1.59$)$ \\
$\quad$ Oesophagus & 12 & 6.10 & $1.97(1.01$ to 3.45$)$ \\
Liver & 7 & 4.65 & $1.51(0.60$ to 3.12$)$ \\
Pancreas & 10 & 9.80 & $1.02(0.49$ to 1.88$)$ \\
Stomach & 23 & 16.75 & $1.37(0.87$ to 2.06$)$ \\
Colorectal & 38 & 32.69 & $1.16(0.82$ to 1.60$)$ \\
All respiratory cancers & 88 & 65.62 & $1.34(1.08$ to 1.65$)$ \\
Nose and nasal sinuses & 2 & 0.41 & $4.92(0.46$ to 18.10$)$ \\
Larynx & 5 & 2.21 & $2.26(0.71$ to 5.31$)$ \\
Lung & 78 & 62.57 & $1.25(0.99$ to 1.56$)$ \\
$\quad$ Pleura & 3 & 0.46 & $6.58(1.24$ to 19.49$)$ \\
Melanoma & 3 & 5.26 & $0.57(0.11$ to 1.69$)$ \\
Connective tissue & 4 & 1.07 & $3.73(0.97$ to 9.64$)$ \\
Prostate & 18 & 16.83 & $1.07(0.63$ to 1.69$)$ \\
Testis & 4 & 1.27 & $3.15(0.82$ to 8.14$)$ \\
Bladder & 5 & 5.80 & $0.86(0.27$ to 2.03$)$ \\
Kidney & 5 & 7.24 & $0.69(0.22$ to 1.62$)$ \\
Eye & 1 & 0.31 & $3.22(0.00$ to 18.48$)$ \\
Brain and nervous system & 3 & 7.00 & $0.43(0.08$ to 1.27$)$ \\
Hodgkin's disease & 3 & 1.81 & $1.66(0.31$ to 4.91$)$ \\
Non-Hodgkin's lymphoma & 3 & 5.42 & $0.55(0.10$ to 1.64$)$ \\
Multiple myeloma & 2 & 2.97 & $0.67(0.06$ to 2.48$)$ \\
Leukaemia & 6 & 6.86 & $0.87(0.31$ to 1.92$)$ \\
\hline
\end{tabular}

naphthenic mineral oils. In 1975, paraffinic oils were introduced into the railway industry, these being waxy, straight chain oils with very low concentrations of aromatic compounds. In the foundry, iron and steel castings have been produced in the same foundry area and workers could work in both areas as required.

Vital status was determined from electoral rolls, vehicle registration records, and personal knowledge of current employees in a few cases. All deaths were determined from death registration records held by the Department of Justice. Those people who were not followed up to the end of 1991 were censored according to the date of last employment or date of last known vehicle registration. Causes of death were coded to the international classification of diseases (ICD) codes in use during the period by an experienced nosologist. ${ }^{10}$ Occupations as recorded on the personnel files and death registration records were coded to the New Zealand standard classification of occupations (New Zealand SCO). ${ }^{11}$

Five year age and time specific mortalities for New Zealand men were used to estimate the expected number of deaths to calculate standardised mortality ratios (SMRs). The data were analysed with the PERSONYEARS program for the analysis of cohort studies. ${ }^{12}$ Ninety five per cent confidence intervals (95\% CIs) were calculated assuming a Poisson distribution. The $\chi^{2}$ test for linear trend was as described by Breslow and Day. ${ }^{13}$

\section{Results}

The cohort numbered 3522 men with $57.9 \%$ known to be alive, and $28.3 \%$ determined as dead by the end of 1991 . The follow up was $86.2 \%$. The follow up by person-years is given by the ratio of the total person-years of follow up actually achieved (85 592 person-years) to that of the number of person-years which would have been achieved if, for all subjects, follow up had continued until 31 December 1991 or the untraced man would have reached 85 years, whichever occurred first. ${ }^{1}$ This theoretical number was 95555 person-years, so that the follow up achieved was $89.6 \%$ of total person-years. Of those determined as alive, $1.28 \%$ were identified from personal knowledge of current employees.

The SMRs for the total workforce are shown in table 1, for the major causes of death, with more detail for respiratory diseases. Significantly increased SMRs were found for all causes of death combined, all cancers, circulatory diseases, and diseases of the musculoskeletal system and connective tissue. There was a significant deficit in deaths from endocrine, nutritional, and metabolic causes. Foundry workers did not have an increased SMR for non-malignant respiratory diseases (SMR 0.81; 95\% CI 0.29 to 1.77 .

The SMRs for malignant causes of death are shown in table 2. Significantly increased SMRs were found for all digestive cancers combined and all respiratory cancers combined, cancer of the oesophagus, and mesothelioma of the pleura. The SMRs for cancer of the lung and connective tissue were increased and nearly 
Table 3 SMRs for selected causes of death by exposure to asbestos, machining fluids, and foundry work (total workforce)

\begin{tabular}{|c|c|c|c|c|c|c|}
\hline \multirow[b]{2}{*}{ Exposure group } & \multicolumn{6}{|c|}{ Cause of death } \\
\hline & Obs & $\operatorname{SMR}(95 \% C I)$ & Obs & $S M R(95 \% C I)$ & Obs & $S M R(95 \% C I)$ \\
\hline Asbestos: & \multicolumn{2}{|c|}{ All causes } & \multicolumn{2}{|c|}{ All cancers } & Lung & cancer \\
\hline Nil & 232 & $1.03(0.90$ to 1.17$)$ & 55 & $1.09(0.82$ to 1.42$)$ & 17 & 1.15 (0.67 to 1.85$)$ \\
\hline Low & 115 & $1.14(0.94$ to 1.37$)$ & 26 & $1.13(0.74$ to 1.65$)$ & 9 & $1.32(0.60$ to 2.52$)$ \\
\hline Medium & 252 & $0.90(0.79$ to 1.02$)$ & 61 & $0.96(0.73$ to 1.23$)$ & 16 & $0.88(0.50$ to 1.43$)$ \\
\hline High & 88 & $1.18(0.94$ to 1.45$)$ & 21 & $1.21(0.75$ to 1.85$)$ & 5 & 0.97 (0.31 to 2.28$)$ \\
\hline Mixed & 309 & $1.24(1.11$ to 1.39$)$ & 84 & $1.41(1.13$ to 1.75$)$ & 31 & $1.76(1.19$ to 2.50$)$ \\
\hline Machining fluids: & \multicolumn{2}{|c|}{ All causes } & \multicolumn{2}{|c|}{ All cancers } & \multicolumn{2}{|c|}{ All digestive cancers } \\
\hline Nil & 27 & $1.38(0.91$ to 2.01$)$ & 8 & $1.80(0.77$ to 3.55$)$ & 4 & $2.73(0.71$ to 7.05$)$ \\
\hline Low & 368 & $1.07(0.96$ to 1.18$)$ & 90 & $1.15(0.92$ to 1.41$)$ & 33 & $1.29(0.88$ to 1.81$)$ \\
\hline Medium & 173 & $0.86(0.73$ to 1.00$)$ & 36 & $0.79(0.55$ to 1.09$)$ & 15 & $1.02(0.57$ to 1.68$)$ \\
\hline High & 119 & $1.03(0.86$ to 1.24$)$ & 29 & $1.11(0.74$ to 1.60$)$ & 8 & $0.94(0.40$ to 1.86$)$ \\
\hline Mixed & 309 & $1.24(1.11$ to 1.39$)$ & 84 & $1.41(1.13$ to 1.75$)$ & 30 & 1.56 (1.05 to 2.22$)$ \\
\hline Foundry work: & \multicolumn{2}{|c|}{ All causes } & \multicolumn{2}{|c|}{ All cancers } & Lung & cancer \\
\hline Not exposed & 611 & $1.00(0.92$ to 1.08$)$ & 147 & $1.06(0.89$ to 1.24$)$ & 42 & $1.04(0.75$ to 1.40$)$ \\
\hline Exposed & 76 & $1.09(0.86$ to 1.36$)$ & 16 & $1.03(0.59$ to 1.67$)$ & 5 & $1.11(0.35$ to 2.62$)$ \\
\hline Mixed & 309 & $1.24(1.11$ to 1.39$)$ & 84 & $1.41(1.13$ to 1.75$)$ & 31 & $1.76(1.19$ to 2.50$)$ \\
\hline
\end{tabular}

reached significance. There were no deaths from peritoneal mesothelioma. Labourers had an increased SMR for lung cancer (SMR 1.74; $95 \%$ CI 1.18 to 2.48 ). Within the occupational group metal processors all the lung cancer deaths occurred among the subset of moulders with an SMR of 1.54 (95\% CI 0.48 to 3.61). There were no increased risks of mortality for any of the digestive cancers among turners and machine tool operators. No deaths from colorectal cancer occurred among the pattern makers in the cohort.

Three deaths from pleural mesothelioma occurred among the cohort. All of these men had been first employed in the 1920s in their teens, and had worked at the plant for $\geqslant 40$ years. The empirical induction times (latency period) were 57,53 , and 51 years. ${ }^{14}$ The crude mortality from pleural mesothelioma in those with any asbestos exposure was $0.87 / 1000$ men. Apart from the one death recorded as due to asbestosis three other workers had lung fibrosis or interstitial lung disease recorded as a contributing cause of death on the death registration record. All four men worked in insulating areas. Two of these men had spent most of their working lives at the plant and been first exposed at young ages.

The data for selected causes of death by exposure category are shown in table 3 . There were no trends of increasing risk for any cause of death with increasing exposure to asbestos, machining fluids, or foundry work.

Among all workers in the plant who had any potential exposure to asbestos (that is, all except administrative workers), there was no

Table 4 SMRs for all causes of death combined and lung cancer by duration of employment in the plant (total workforce excluding administrative workers)

\begin{tabular}{lrlll}
\hline $\begin{array}{l}\text { Duration of } \\
\text { employment in plant } \\
(y)\end{array}$ & Group $(n)$ & $\begin{array}{l}\text { Observed deaths } \\
(n)\end{array}$ & $\begin{array}{l}\text { Expected deaths } \\
(n)\end{array}$ & SMR (95\% CI) \\
\hline $\begin{array}{l}\text { All causes of death: } \\
\quad 5\end{array}$ & 1724 & 391 & 326.75 & $1.20(1.08$ to 1.32$)$ \\
$5-9$ & 738 & 169 & 158.18 & $1.07(0.91$ to 1.24$)$ \\
$10-19$ & 507 & 191 & 191.80 & $1.00(0.86$ to 1.15$)$ \\
$\geqslant 20$ & 472 & 219 & 233.78 & $0.94(0.82$ to 1.07$)$ \\
$\quad$ Total & 3441 & 970 & 910.52 & $1.07(1.00$ to 1.13$)$ \\
Lung cancer: & 1724 & 35 & 22.32 & $1.57(1.09$ to 2.18$)$ \\
$<5$ & 738 & 18 & 10.03 & $1.79(1.06$ to 2.84$)$ \\
$5-9$ & 507 & 10 & 12.53 & $0.80(0.38$ to 1.47$)$ \\
$10-19$ & 472 & 13 & 16.39 & $0.79(0.42$ to 1.36$)$ \\
$\geqslant 20$ & 3441 & 76 & 61.27 & $1.24(0.98$ to 1.55$)$ \\
$\quad$ Total & & & & \\
\hline
\end{tabular}

dose-response effect noted for all causes of death combined and lung cancer when SMRs were calculated by increasing duration of employment in the plant (table 4). There were, however, significant trends of decreasing SMR with increasing duration of employment in the plant for all causes of death combined $\left(\chi^{2}\right.$ test for linear trend $=9.54, \mathrm{df}=1, \mathrm{p}=0.002$ ) and lung cancer $\left(\chi^{2}\right.$ test for linear trend $=6.65, \mathrm{df}=1$, $\mathrm{p}=0.010$ ), with those with $<10$ years employment having the highest risks.

The data for all causes of death, all malignancies and lung cancer were also analysed for 10 and 20 year lag periods and period of employment, with no particular associations being noted.

\section{Discussion}

In this study, we found small but significant increases in risk for all causes of death, all malignancies, circulatory diseases, diseases of the musculoskeletal system and connective tissue, cancers of the digestive and respiratory systems, cancer of the oesophagus, and pleural mesothelioma in the total workforce. The risk of dying from lung cancer in the total workforce was increased and suggestive of an association. This study had a $99 \%$ probability of detecting a significant increase $(\alpha=0.05)$ in lung cancer in the total workforce if the true relative risk was 1.5 . The follow up was $86 \%$ of men, or $90 \%$ of possible person-years. The only other cohort study carried out in New Zealand obtained a follow up of $89.5 \%$ of men in a defence forces population. ${ }^{1}$ Determining vital status in New Zealand is difficult as death registration records were not computerised until 1997 and death certificate data held by the Ministry of Health were incomplete, hence all death registrations were retrieved manually. Electoral roll and vehicle registration records were computerised.

Some selection bias may have remained, despite the follow up of $90 \%$ of person-years. If those untraced were less likely to die prematurely from a cause such as circulatory disease compared with those traced, then the observed SMR would be an overestimate. However, the observed SMR of 1.16 for circulatory diseases in the $90 \%$ followed up, means that the SMR in the whole cohort would still be increased even 
if there were no such deaths among the untraced men, which is highly unlikely. Of those known to be alive, only $1.28 \%$ were identified by personal knowledge of current employees. This proportion was too small to have introduced any bias, and only those who could be absolutely identified as alive were accepted.

No dose-response relations were found between increasing exposure to asbestos and all causes of death, all cancers, and lung cancer, or between exposure to machining fluids and all causes of death, all cancers, and all digestive cancers. Similarly, no dose-response relations were found between increasing duration of employment in the plant and all causes of death and lung cancer. However, there was evidence of a type of selection effect as there were significant trends of decreasing SMR for all causes of death and lung cancer with increasing duration of employment in the plant, with those with $<10$ years employment having the highest risks. This may be due to short term workers (often labourers) leading more at risk lifestyles and they may have been given the dirtiest jobs. ${ }^{14} 15$

There was evidence of disease related to asbestos among the cohort with three deaths from pleural mesothelioma, and a few deaths where asbestosis or lung fibrosis were noted on the death certificates. Pleural mesothelioma tends to be underreported, possibly by as much as $80 \%$ so it is likely that more deaths occurred from mesothelioma in the cohort than were recorded. ${ }^{16}$ The observation of disease related to asbestos in the New Zealand cohort was similar to findings in Swedish and American cohorts where increased risks of pleural mesothelioma in workers exposed to chrysotile were also found. ${ }^{8}{ }^{17}$ These New Zealand data did not show an increased risk for lung cancer in the group with the highest exposure to asbestos. Swedish workers with similar exposures, employed for $\geqslant 30$ years, had a significantly increased SMR for lung cancer. ${ }^{8}$ Five deaths from pleural mesothelioma occurred in the Swedish cohort of 3442 men, the average empirical induction time being 44 years. The United States cohort identified eight cases of pleural mesothelioma in 197 railway machinists whose average empirical induction time was 51 years. ${ }^{17}$ These times are similar to the New Zealand cohort, in which the average empirical induction time was 54 years. The crude pleural mesothelioma mortality in the Swedish study was $1.5 / 1000$ and in the New Zealand cohort it was $0.87 / 1000 .^{8}$

Smoking is an important cause of lung cancer, other respiratory diseases, and cardiovascular disease. Unfortunately, the prevalence of smoking was unknown among the cohort. Smoking cannot be excluded as the reason for the increased risk for lung cancer in the total workforce, or in different occupational groups.

This study was limited by lack of data on past exposure, this being a common problem in historical occupational cohort studies. Duration of employment in particular jobs is a crude surrogate for exposure. Men were classified according to the job that they held longest, which may have led to an underestimation of exposure. ${ }^{14}$ Not being able to place men into clearly different levels of exposure may underestimate any risk and remove evidence of a dose-response relation. This means that the SMRs in this study for specific occupational groups may have been underestimated because of the lack of exposure measurements and poor estimation of dose. ${ }^{14}$

Foundry moulders had a slightly increased SMR for lung cancer, although this was not significant. Other studies of moulders have found an increased risk of lung cancer. ${ }^{18} 1920$ Foundry work has been classified by the IARC as being carcinogenic to humans with a relative risk of lung cancer in the range of 1.5-2.5. Moulders may be exposed to PAHs, metal fumes including nickel and chromium, and various other breakdown products from pyrolysis from the sand binders and additives. ${ }^{25}$ The New Zealand foundry workers did not have an increased SMR for non-malignant respiratory diseases. Studies of other groups of foundry workers have tended to find increased risks of non-malignant respiratory diseases, but this is not a consistent finding. ${ }^{182}$ An association between pattern making and colorectal cancer has been found in various studies: however, no deaths from colorectal cancer occurred among the pattern makers in the New Zealand cohort. ${ }^{23} 24$

In the New Zealand cohort, those men with the highest exposure to machining fluids had no significantly increased SMRs for any cancer site. The number of deaths was small, and only for lung cancer were there more than five deaths. The IARC has listed the untreated and mildly treated mineral oils as having sufficient evidence of being carcinogenic in humans, with inadequate evidence for the carcinogenicity in humans of the highly refined oils. ${ }^{35}$ Exposure to machining fluids by working populations has been most commonly associated with nonmelanotic skin cancer, non-malignant respiratory diseases, and cancers of the respiratory and digestive systems. ${ }^{4525-29}$ Recent studies carried out in the United States found no significantly increased risks of cancers of the colon in car workers exposed to machining fluids but significant increases were found for cancers of the oesophagus, stomach, rectum, pancreas, larynx, lung, prostate, and leukaemia. ${ }^{4} 27$

This study found an increased risk of mortality (although non-significant) for cancers of connective tissue with four deaths found. Little is known about the causes of these types of cancers and their incidence has been increasing in recent years. ${ }^{30}$ All four of the men were likely to have been exposed to machining fluids; however, the histology recorded differed between them, with two sarcomas, one histiocytoma, and one squamous cell carcinoma.

The study also found a significantly increased SMR for diseases of the musculoskeletal system and connective tissue. This may reflect the selection of workers into this particular workforce as the plant concerned was known locally as one which was prepared to employ men with impaired health. ${ }^{14}$ The 
increase in risk of circulatory diseases may also reflect this selection effect.

The data were also analysed for 10 and 20 year lag periods and period of employment, with no particular associations being noted.

This study of a New Zealand cohort of foundry and heavy engineering workers in the railway rolling stock manufacturing industry found small increases in risk for several causes of death; however, these increases were small and the possible effects of smoking and other lifestyle factors could not be excluded. There was evidence of disease related to asbestos in those involved in engineering work in the past. We thank all past and present employees for their help in
carrying out this study. We also thank associate professor Neil carrying out this study. We also thank associate professor Neil
Pearce for providing some of the national male mortality data Pearce for providing some of the national male mortality data
formatted for the PERSONYEARS programme. This study was funded by the Cancer Society of New Zealand and the Health funded by the Cancer Society of N
Research Council of New Zealand.

1 Pearce N, Prior I, Methven D, et al. Follow up of New Zealand participants in British atmospheric nuclear weapons tests in the Pacific. BMF 1990;300:1161-6.

2 International Agency for Research on Cancer. Polynuclear aromatic compunds, Part 3, industrial exposures in aluminium production, coal gasification, coke production, and iron and steel founding. IARC Monogr Eval Carcinog Risk Chem Humans 1984;34:133-90.

3 International Agency for Research on Cancer. Polynuclear aromatic compounds, Part 2, carbon blacks, mineral oils and some nitroarenes. IARC Monogr Eval Carcinog Risk Chem Humans 1984;33:87-168.

4 Eisen E, Tolbert P, Monson R, et al. Mortality studies of machining fluid exposure in the automobile industry I: a standardised mortality ratio analysis. Am $\mathcal{F}$ Ind Med 1992;22:809-24.

5 International Agency for Research on Cancer. Overall evaluations of carcinogenicity: an updating of IARC monoevaluations of carcinogenicity: an updating of IARC mono-
graphs. Vols 1-42. IARC Monogr Eval Carcinog Risk Chem graphs. Vols 1-42. IARC
Humans 1987; (suppl 7)

6 Doll R, Peto J. Effects on health of exposure to asbestos. London: Health and Safety Commission, 1985.

7 McDonald JC. Mineral dusts and fibres. In: McDonald JC, ed. Epidemiology of work related diseases. London: BMJ Publishing Group, 1995:87-116.

8 Ohlson C, Klaesson B, Hogstedt C. Mortality among asbestos exposed workers in a railroad workshop. Scand $\mathcal{F}$ Work Environ Health 1984;10:283-91.

9 Mancuso TF. Relative risk of mesothelioma among railroad machinists exposed to chrysotile. Am F Ind Med 1988;13: 639-57.

10 World Health Organization. International classification of diseases, 6-9th CM revision. Geneva: WHO, 1938-79.
11 Department of Statistics. New Zealand standard classifications of occupations. Wellington: Department of Statistics, 1976. 2 Coleman M, Hermon C, Douglas A. Manual for PYRS: cohort study analysis program (version 1.3). Lyon: IARC, 1989 .

13 Breslow NE, Day NE. Statistical methods in cancer research: the design and analysis of cohort studies. IARC Sci Publ 1987;82.

14 Checkoway H, Pearce NE, Crawford-Brown DJ. Research methods in occupational epidemiology. Oxford: Oxford University Press, 1989

15 Peto J, Doll R, Hermon C, et al. Relationship of mortality to measures of environmental asbestos pollution in an asbestos textile factory. Ann Occup Hyg 1985;29:305-55.

16 Selikoff IJ. Use of death certificates in epidemiological studies, including occupational hazards: discordance with clinical and autopsy findings. Am f Ind Med 1992;22:469-80.

17 Mancuso TF. Relative risk of mesothelioma among railroad machinists exposed to chrysotile. Am f Ind Med 1988;13: 639-57.

18 Koskela R, Hernberg S, Karava R, et al. A mortality study of foundry workers. Scand $\mathcal{f}$ Work Environ Health 1976; 2(suppl 1):73-89

19 Hansen E. Cancer mortality among Danish moulders. Am $\mathcal{F}$ Ind Med 1991;20:401-9.

20 Sorahan T, Faux A, Cooke M. Mortality among a cohort of UK steel foundry workers with special reference to cancers of the stomach and lung, 1946-90. Occup Environ Med 1994;51:316-22.

21 Hanson ES. A cohort mortality study of foundry workers. Am f Ind Med 1997;32:223-33.

22 Andjelkovich DA, Mathew RM, Richardson RB, et al. Mortality of iron foundry workers: I. Overall findings. $\mathcal{F}$ Occup Med 1990;32:529-40.

23 Swanson GM, Belle SH. Cancer morbidity among woodworkers in the US automotive industry. $\mathcal{F} \mathrm{Occ} M e d$ 1982;24:315-9.

24 Tilley B, Johnson C, Schultz L, et al. Risk of colorectal cancer among automotive pattern and model makers. $\mathcal{F}$ Occup Med 1990;32:541-6.

25 Decoufle P. Analysis of cancer mortality patterns among workers exposed to cutting oil mists. $\mathcal{F}$ Natl Cancer Inst 1978;61:1025-30.

26 Jarvholm B, Lavenius B. Mortality and cancer morbidity in workers exposed to cutting fluids. Arch Environ Health 1987;42:361-6.

27 Tolbert P, Eisen E, Pothier L, et al. Mortality studies of machining-fluid exposure in the automobile industry. II Risks associated with specific fluid types. Scand 7 Work Environ Health 1992;18:351-60.

28 Rosenman KD, Reilly MJ, Kalinowski D. Work-related asthma and respiratory symptoms among workers exposed to metal-working fluids. Am f Ind Med 1997;32:325-31.

29 Sprince NL, Thorne PS, Popendorf W, et al. Respiratory symptoms and lung function abnormalities among machine operators in automobile production. Am f Ind Med 1997;31:403-13.

30 Hoar Zahm S, Tucker MA, Fraumeni JF. Soft tissue sarcomas. In: Schottenfeld D, Fraumeni JF, eds. Cancer epidemiology and prevention. Oxford: Oxford University Press, $1996 ; 984-99$

\section{Correspondence and editorials}

Occupational and Environmental Medicine welcomes correspondence relating to any of the material appearing in the journal. Results from preliminary or small scale studies may also be published in the correspondence column if this seems appropriate. Letters should be not more than 500 words in length and contain a minimum of references. Tables and figures should be kept to an absolute minimum. Letters are accepted on the understanding that they be subject to editorial revision and shortening.

The journal also publishes editorials which are normally specially commissioned. The Editor welcomes suggestions regarding suitable topics; those wishing to submit an editorial, however, should do so only after discussion with the Editor. 